This document was prepared in conjunction with work accomplished under Contract No. DE-AC09-96SR18500 with the U.S. Department of Energy.

This work was prepared under an agreement with and funded by the U.S. Government. Neither the U. S. Government or its employees, nor any of its contractors, subcontractors or their employees, makes any express or implied: 1 . warranty or assumes any legal liability for the accuracy, completeness, or for the use or results of such use of any information, product, or process disclosed; or 2 . representation that such use or results of such use would not infringe privately owned rights; or 3 . endorsement or recommendation of any specifically identified commercial product, process, or service. Any views and opinions of authors expressed in this work do not necessarily state or reflect those of the United States Government, or its contractors, or subcontractors. 
Proceedings of PVP2008-61564

2008 ASME Pressure Vessels and Piping Division Conference

July 27-31, 2008, Chicago, Illinois

WSRC-STI-2008-00229

PVP2008-61564

\title{
Dynamic Analysis of Hanford Unirradiated Fuel Package Subjected to Sequential Lateral Loads in Hypothetical Accident Conditions
}

\author{
Tsu-te Wu \\ Jennifer L. Gorczyca \\ Daniel R. Leduc \\ Jeffery L. England \\ Savannah River National Laboratory \\ Aiken, South Carolina 29803 \\ (803) 725-8201, tsu-te.wu@srnl.doe.gov
}

\begin{abstract}
Large fuel casks present challenges when evaluating their performance in the Hypothetical Accident Conditions (HAC) specified in the Code of Federal Regulations Title 10 part 71 (10CFR71). Testing is often limited by cost, difficulty in preparing test units and the limited availability of facilities which can carry out such tests. In the past, many casks were evaluated without testing by using simplified analytical methods.
\end{abstract}

This paper presents a numerical technique for evaluating the dynamic responses of large fuel casks subjected to sequential HAC loading. A nonlinear dynamic analysis was performed for a Hanford Unirradiated Fuel Package (HUFP) [1] to evaluate the cumulative damage after the hypothetical accident Conditions of a 30-foot lateral drop followed by a 40-inch lateral puncture as specified in 10CFR71. The structural integrity of the containment vessel is justified based on the analytical results in comparison with the stress criteria, specified in the ASME Code, Section III, Appendix F [2], for Level D service loads.

The analyzed cumulative damages caused by the sequential loading of a 30 -foot lateral drop and a 40-inch lateral puncture are compared with the package test data. The analytical results are in good agreement with the test results.

\section{INTRODUCTION}

Large fuel casks are required to comply with the acceptable criteria for the hypothetical accident conditions defined in 10 CFR 71. The HAC events occur sequentially as follows.

1. The package falls 30 feet from the bridge to impact an essentially rigid road surface below.

2. The package bounces into the air and upon descent falls 40 inches to impact a broken axle stub.

This paper presents a numerical technique to predict the cumulative damages of large fuel casks subjected to the sequential HAC dynamic loads described above. The equipment evaluated is the Hanford unirradiated fuel package.

\section{ANALYSIS}

The structural response of the HUFP to the sequential loading of a 30-foot drop followed by a 40-inch puncture was simulated by performing nonlinear dynamic finiteelement analysis with explicit time integration.

The ABAQUS/Explicit Computer Code, version 6.6-3 [3], was used to perform the computations. The finite-element meshes of the containment vessel, the impact limiters and the impact limiter shells were generated using the MSC/PATRAN computer program [4]. The finite-element models of the core component container (CCC) and the core component container adapter were originally used in the analysis reported in Reference 1 and generated by the LS-DYNA computer code [5]. The LS-DYNA model was modified and imported into the MSC/PATRAN model. 


\section{Finite-Element Model}

Figure 1 shows the sketch of a HUFP which was analyzed. Since the geometrical configuration and the loading conditions are symmetric with respect to a certain plane passing through the axis of the package, the finite-element model need only include one half of the package. The principal components and their materials are given in Table 1.

Table 1. Components and Materials of HUFP Model

\begin{tabular}{|c|c|c|}
\hline $\begin{array}{l}\text { Item } \\
\text { Number }\end{array}$ & Description & Material \\
\hline 1 & $\begin{array}{l}\text { Containment } \\
\text { Vessel }\end{array}$ & $\begin{array}{l}\text { ASTM SA240, XM- } \\
19\end{array}$ \\
\hline 2 & $\begin{array}{l}\text { Core } \\
\text { component } \\
\text { container } \\
\end{array}$ & $\begin{array}{l}\text { ASTM SA240, Type } \\
304\end{array}$ \\
\hline 3 & $\begin{array}{l}\text { Core } \\
\text { component } \\
\text { container } \\
\text { adapter }\end{array}$ & $\begin{array}{l}\text { ASTM SA240, Type } \\
304\end{array}$ \\
\hline 4 & $\begin{array}{l}\text { Lid End Impact } \\
\text { Limiter }\end{array}$ & $\begin{array}{l}10 \text { lb Polyurethane } \\
\text { Foam }\end{array}$ \\
\hline 5 & $\begin{array}{l}\text { Bottom End } \\
\text { Impact Limiter }\end{array}$ & $\begin{array}{l}10 \text { lb Polyurethane } \\
\text { Foam }\end{array}$ \\
\hline 6 & $\begin{array}{l}\text { Lid End Impact } \\
\text { Limiter Shell }\end{array}$ & $\begin{array}{l}\text { ASTM SA240, Type } \\
304\end{array}$ \\
\hline 7 & $\begin{array}{l}\text { Bottom End } \\
\text { Impact Limiter } \\
\text { Shell }\end{array}$ & $\begin{array}{l}\text { ASTM SA240, Type } \\
304\end{array}$ \\
\hline 8 & Floor & $\begin{array}{l}\text { Unyielding Rigid } \\
\text { Surface }\end{array}$ \\
\hline 9 & $\begin{array}{l}\text { 6-Inch Round } \\
\text { Steel Bar }\end{array}$ & $\begin{array}{l}\text { Unyielding Bar } \\
\text { Assumed }\end{array}$ \\
\hline
\end{tabular}

The finite-element models of the containment vessel, the impact limiter shells and the core component container adapter are comprised of three dimensional shell elements (Type S4R elements in the ABAQUS Computer Code). The impact limiters and the core component container are modeled using 3D brick elements (Type C3D8R). The target rigid floor and the puncture bar are also modeled by the $3 \mathrm{D}$ brick elements that are then made rigid. Figure 2 is the overall finite-element model of the package. In order to avoid the interference between the package model and the puncture bar model during the 30-foot drop simulation, the puncture bar is placed 20.82 inches below the outer surface of the containment vessel. Therefore, during the 40-inch puncture analysis, the package actually falls 60.82 inches onto the puncture.

\section{$\underline{\text { Applied Load and Initial Condition }}$}

The downward gravitational force of the falling package is represented by the gravitational load of $386.4 \mathrm{in} / \mathrm{sec}^{2}$ in the positive " $\mathrm{X}$ " direction of the model.

The package is initially located near the target floor so that the initial velocity is equal to the velocity of the package after a 30-foot free fall in the positive " $\mathrm{X}$ " direction of the model. Therefore, the initial velocity can be calculated as follows.

$$
V_{0}=\sqrt{2 g h}=\sqrt{2 \times 386.4 \frac{\text { in }}{\mathrm{sec}^{2}} \times 12.0 \frac{\mathrm{in}}{\mathrm{ft}} \times 30 \mathrm{ft}}=527.454 \frac{\mathrm{in}}{\mathrm{sec}}
$$

\section{Boundary Conditions}

Due to the symmetrical conditions of the geometry and loading, the following boundary conditions are applied at the nodes on the symmetrical plane along the axis of the package:

$\mathrm{UY}=0 ; \quad \mathrm{RX}=0 ; \quad \mathrm{RZ}=0$

where UY, RX and RZ denote translation in Y direction, rotation about $\mathrm{X}$ axis and rotation about $\mathrm{Z}$ axis, respectively.

\section{Contact Conditions}

The contact conditions between the interfaces of the components are simulated by using the general contact options and the penalty method available in ABAQUS Code. However, the interaction between the floor model and the puncture bar model are excluded from the general contact specification so that they will move without interfering with each other.

\section{$\underline{\text { Analytical Procedures }}$}

In order to evaluate the cumulative damage of the HUFP subjected to the sequential loading of a 30 -foot free drop and 40-inch puncture, the analysis consists of the following three load steps.

First Load Step:

The first load step is to analyze the structural response of the package during a 30-foot free drop of the package onto the rigid floor fixed in space. The initial velocity of the package is given in Equation (1). The gravitational load of $386.4 \mathrm{in} / \mathrm{sec}^{2}$ is also immediately applied to the package. 
Second Load Step:

The purpose of the second load step is to determine the onset impact velocity after a 40-inch free drop of the package onto the round bar. The onset impact velocity, in the positive $\mathrm{X}$ direction, corresponding to a 40 -inch free drop is calculated as follows.

$$
V_{0}=\sqrt{2 g h}=\sqrt{2 \times 386.4 \frac{\mathrm{in}}{\mathrm{sec}^{2}} \times 40.0}=175.818 \frac{\mathrm{in}}{\mathrm{sec}}
$$

Since the initial condition has already been defined in the first load step as the onset impact velocity after a 30 -foot free drop, the onset impact velocity for the 40-inch puncture can thus not be specified as an initial velocity any more. Therefore, the onset impact velocity for the 40 -inch free fall of the package is specified as a boundary condition varying with time. The package velocity varies with time from zero to $175.818 \mathrm{in} / \mathrm{sec}$ smoothly so that undesired accelerations will not be generated.

During the second load step, the floor model will move at the velocity of the package so that it will not interfere with the package motion.

Third Load Step:

The third load step is to simulate the structural response of the package to the impact load after a 40 -inch free fall onto a round bar.

\section{STRESS CRITERIA IN ACCORDANCE WITH ASME CODE}

The dynamic load associated with a Hypothetical Accident Condition (HAC) is classified as a Level D Service Load defined in the ASME Code, Section III, Appendix F and the stress limits are defined as follows [2] :

$$
P_{m} \leq 0.7 S_{u}
$$

$P_{L} \leq 0.9 S_{u}$

where $P_{m}=$ General primary membrane stress intensity

$$
P_{L}=\text { Local primary membrane stress intensity }
$$$$
S_{u}=\text { Ultimate strength of material }
$$

The maximum metal temperature under HAC is approximately $200{ }^{\circ} \mathrm{F}$ and the ultimate strength of stainless steel XM-19 is 99.4 psi [1]. Thus, in terms of engineering stresses, the stress limits are as follows.

$P_{m} \leq 0.7 S_{u}=0.7 \times 99.4=69.58 \mathrm{ksi} \quad$ at $200^{\circ} \mathrm{F}$

$$
P_{L} \leq 0.9 S_{u}=0.9 \times 99.4=89.46 \mathrm{ksi} \quad \text { at } 200^{\circ} \mathrm{F}
$$

However, the results of the finite-element analysis are expressed in terms of true stresses and thus, the stress criteria should also be converted to true stresses. Since the engineering strain corresponding to the ultimate strength the stainless steel XM-19 is approximately equal to 0.35 , the true ultimate stresses of the material is:

$$
S_{t u}=S_{u}(\varepsilon+1)=99.4(0.35+1)=134.19 \mathrm{ksi} \text { at } 200{ }^{\circ} \mathrm{F}
$$

where,

$S_{t u}=$ True ultimate stress of stainless steel XM-19

$$
\text { at } 200{ }^{\circ} \mathrm{F}
$$

$\varepsilon=$ Engineering strain corresponding to ultimate strength

Consequently, the stress limits in terms of true stresses are:

$$
\begin{aligned}
& P_{m} \leq 0.7 S_{t u}=0.7 \times 134.19=93.93 \mathrm{ksi} \text { at } 200{ }^{\circ} \mathrm{F} \\
& P_{L} \leq 0.9 S_{t u}=0.9 \times 134.19=120.77 \mathrm{ksi} \text { at } 200{ }^{\circ} \mathrm{F}
\end{aligned}
$$

\section{DISCUSSION ON ANALYTICAL RESULTS}

Figure 3 is the time-history plot of energy variations of the HUFP during the three load steps. The durations for the load steps are: 0.02 seconds for the first load step, 0.01 seconds for the second load step and 0.2 seconds for the third load step.

\section{0-Foot Lateral Drop}

Deformed Shapes of Full Model:

Figure 4 shows the deformed versus undeformed shapes of the package after a 30 -foot drop. The deformed shape is plotted in green; whereas the undeformed shape is plotted in gray. The result shows that the deformations mainly occur in the impact limiters and the impact limiter shells.

Stress and Strain Contours:

Figure 5 shows the von Mises stresses on the middle plane of the containment vessel. The maximum value of the von Mises stresses, $48.35 \mathrm{ksi}$, is less than the allowable limit for the general primary membrane stress intensities. Thus, the structural integrity of the containment vessel after a 30foot drop is justified.

The deformations of the overall HUFP model after a 30foot lateral drop are given in Figure 6. As shown in the 
figure, the impact limiters effectively dissipate most of the kinetic energy.

Figure 7 is the plot of the equivalent plastic strains on the middle plane of the metallic components. The calculated high plastic strains occur in the impact limiter shells.

Figures 8 and 9 show the deformed shapes of the HUFP after a 30 -foot drop test. The test data are generally in good agreement with the analytical results. Since the analysis does consider the stress concentrations caused by the welds and material overlapping at the joints of the impact limiter shells, the material ruptures at the joints are not accounted for.

\section{0-Inch Lateral Puncture}

Stress Distribution:

Figure 10 shows the distribution of von Mises stresses at the instant when the impact force reaches its maximum. As shown in Figure 11, the maximum von Mises stress caused by the 40 -inch lateral puncture is $92.44 \mathrm{ksi}$ and is less than the allowable limit of the general primary membrane stress intensities of $93.93 \mathrm{ksi}$. Since von Mises stresses are either equal to or slightly greater than the Tresca stresses, it is more conservative to compare the maximum von Mises with the allowable limits of stress intensities. As indicated previously, the puncture model actually simulates 60.82-inch free fall instead of 40-inch free fall in order to avoid the interference between the puncture and the package during the 30 -foot drop simulation. As a result, the calculated results are more conservative.

Figure 12 is the plot of stress distribution during the package rebound after the 40 -inch puncture.

\section{Equivalent Plastic Strain Distribution:}

Figure 13 depicts the cumulative damages in the HUFP caused by the sequential loads of a 30 -foot free drop and a 40 -inch puncture. Although the equivalent plastic strains in the impact limiter shells are much higher than those in the containment vessel, the structural integrity of the containment vessel rather than the impact limiter shells is of concern. As shown in Figure 14, the maximum equivalent plastic strain in middle plane of the containment vessel after a 30 -foot drop and a 40 -inch puncture is 0.075 .

\section{Maximum Indentation in Containment Vessel:}

The calculated maximum indentation in the containment vessel caused by a 40-inch puncture as shown in Figure 15 is approximately equal to 3 inches. The test result of the maximum indentation caused by a lateral 40 -inch puncture is shown in Figure 16. As reported in [1], the test value of the maximum indentation is approximately $2 \frac{1}{8}$ inches, which is less than the calculated maximum indentation. Since the analysis actually simulates a 60.82-inch puncture instead of 40-inch puncture for the reason discussed in the section of finite-element model discussion, it is expected that the calculated value is higher than the test result.

\section{CONCLUSIONS}

A nonlinear elastic-plastic analysis was performed for the Hanford irradiated fuel package subjected to the sequential lateral impact loads in the events of hypothetical accident conditions. The analytical results indicate that the structural integrity of the HUFP is maintained during the HAC events.

The analytical results were compared with the 30 -foot lateral drop and the 40-inch lateral puncture test data. In both cases, the analytical and test results are in good agreement.

Since the methodology used predicts the cumulative damages caused by the sequential loads, it may be useful for establishing strain-based failure criteria in the HAC analyses, where the cumulative plastic strains from all the sequential events, rather than each individual event, should be addressed.

\section{REFERENCES}

1. "Hanford Unirradiated Fuel Package (HUFP)," Safety Analysis Report HNF-28554, Revision 0, May 2007.

2. ASME Boiler and Pressure Vessel Code, Division 1, Section III, Appendix F, 2004 Edition, July1, 2004.

3. ABAQUS/Explicit User’s Manual, Version 6.6-3.

4. MSC/PATRAN, Version 2003r2, MacNealSchwendler Corporation.

5. LS-DYNA Computer Program, Version 960, Livermore Software Technology Corporation. 


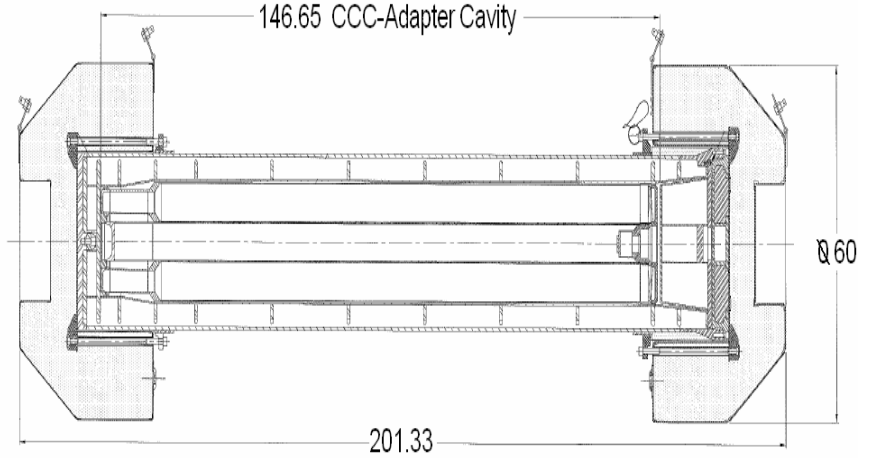

Note: Dimensions in inches.

Figure 1. Geometrical Configuration of HUFP

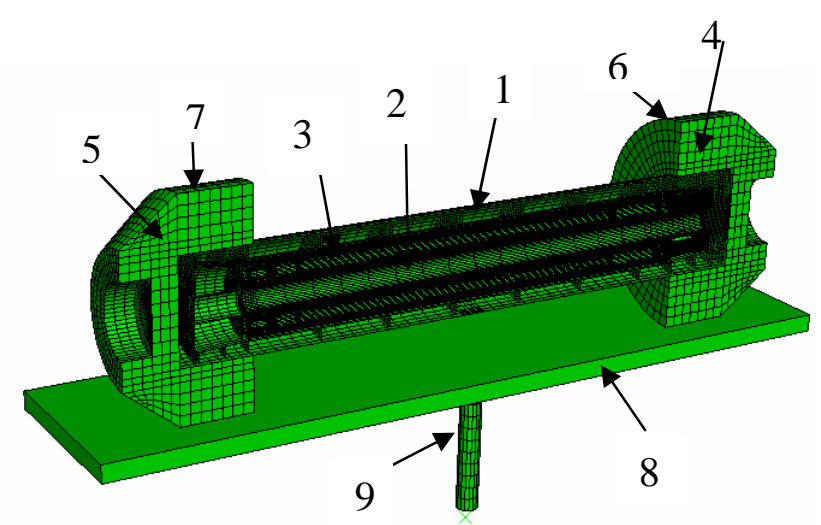

$\sqrt{1}-3$

Figure 2. Finite-Element Model

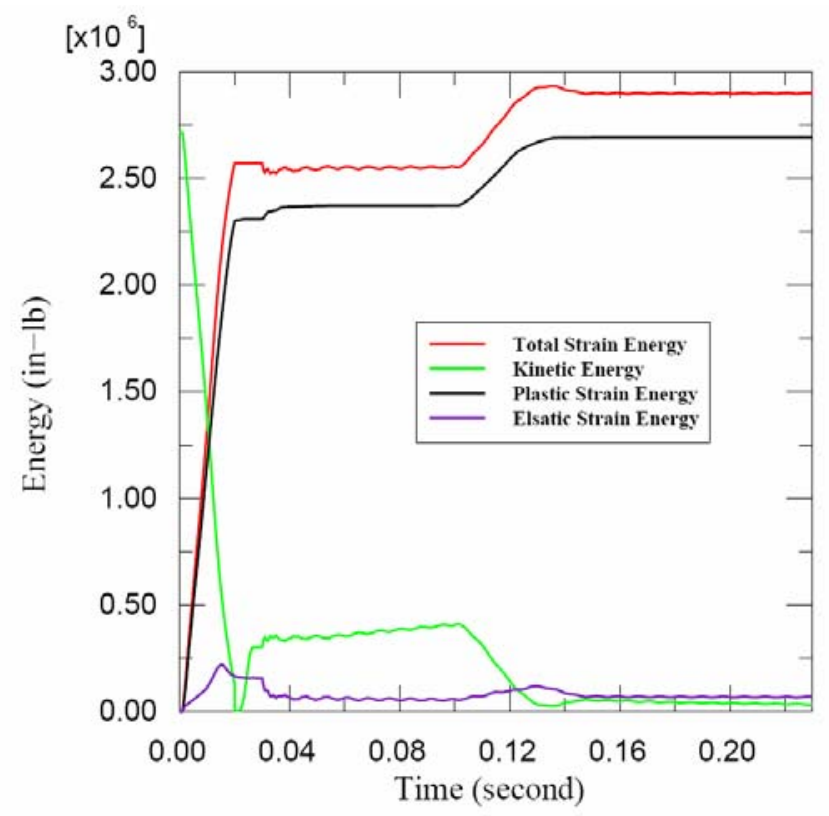

Figure 3. Energy Variations for the 30-Foot Drop and 40-Inch Puncture

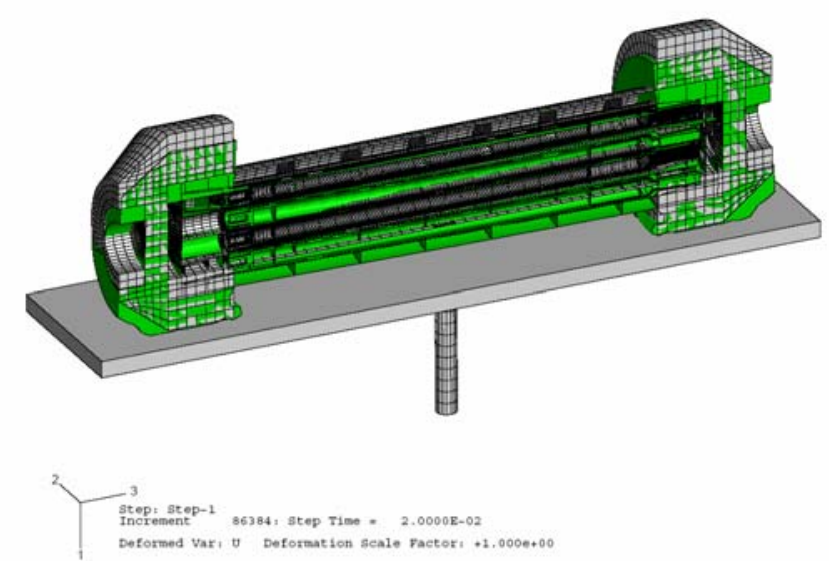

Figure 4. Deformed (in green) and Un-deformed (in gray) Shapes of HUFP after a 30-Foot Lateral Drop

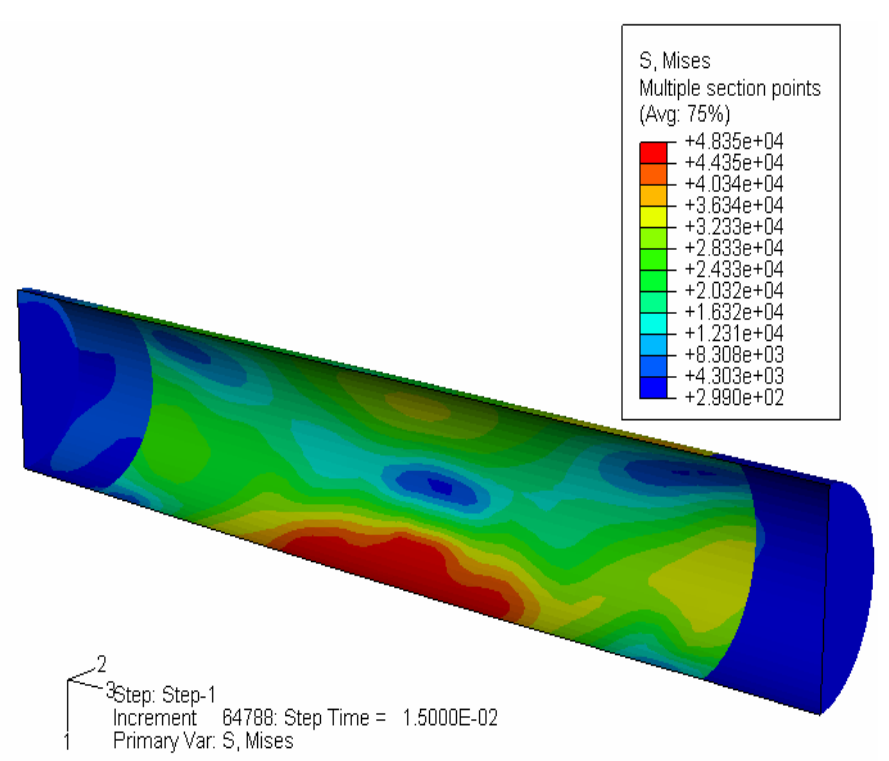

Figure 5. von Mises on the Middle Plane of the Containment Vessel after a 30-Foot Lateral Drop 


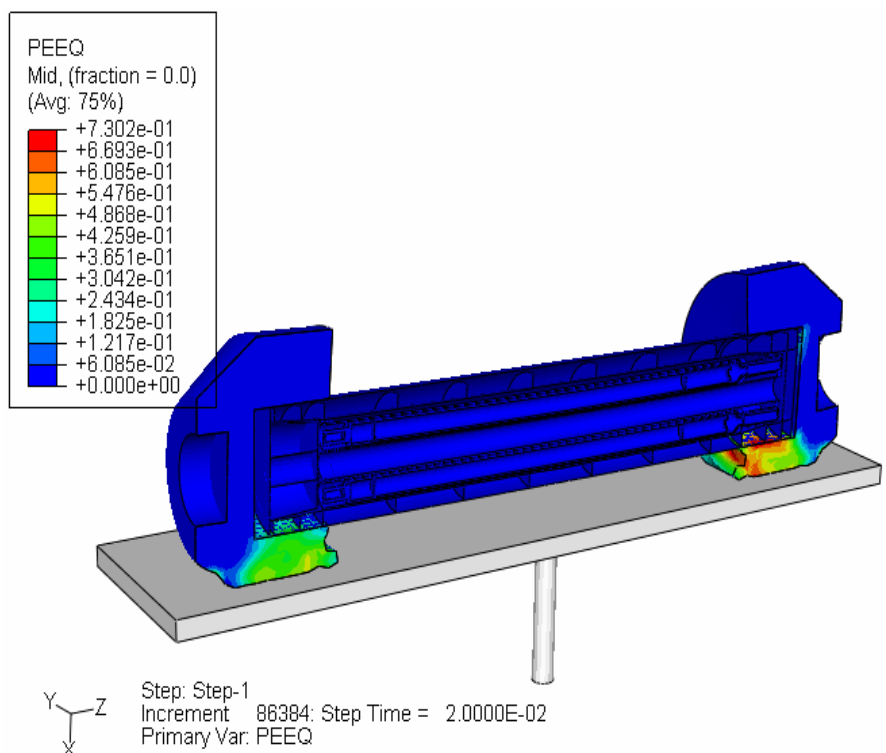

Figure 6. Deformation of the HUFP after a 30-foot Drop

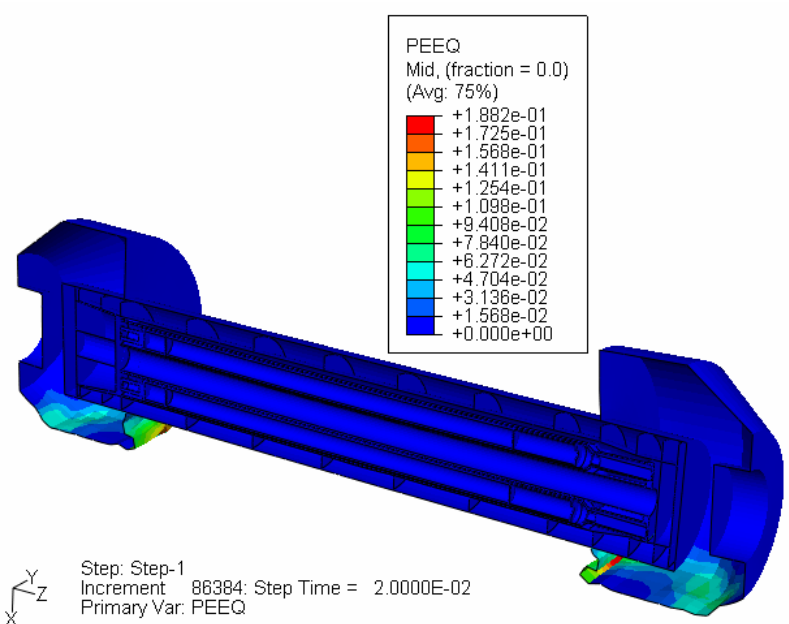

Figure 7. Effective Plastic Strains in the Metallic Components after a 30-Foot Drop

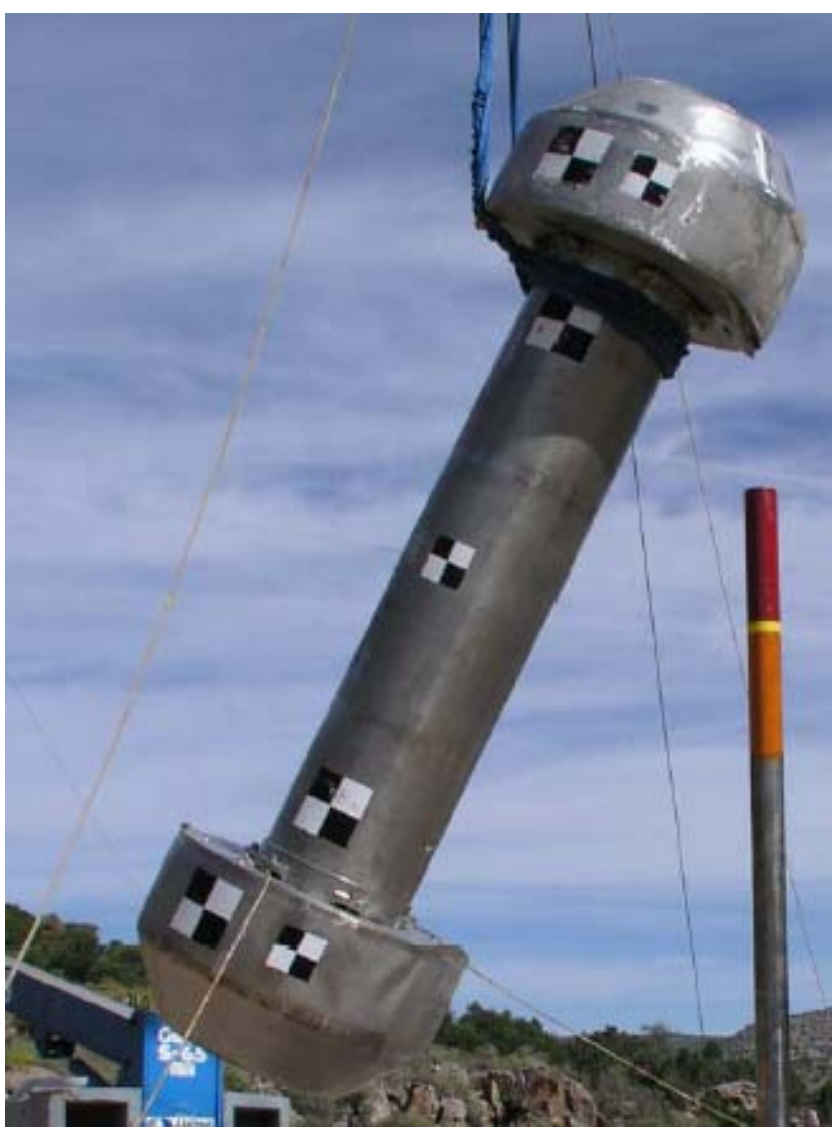

Figure 8. Overall Deformed Shape after a 30-foot Drop Test

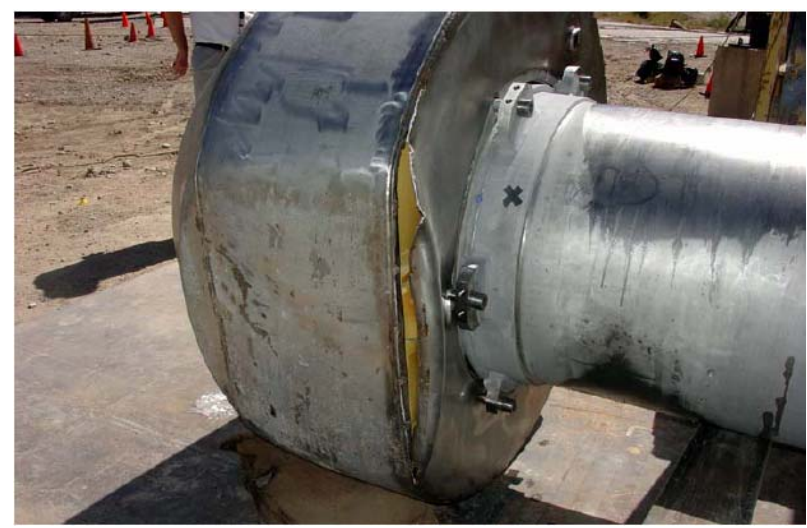

Figure 9. Deformed Shape of Lid-End Impact Limiter After a 30-Foot Drop Test 


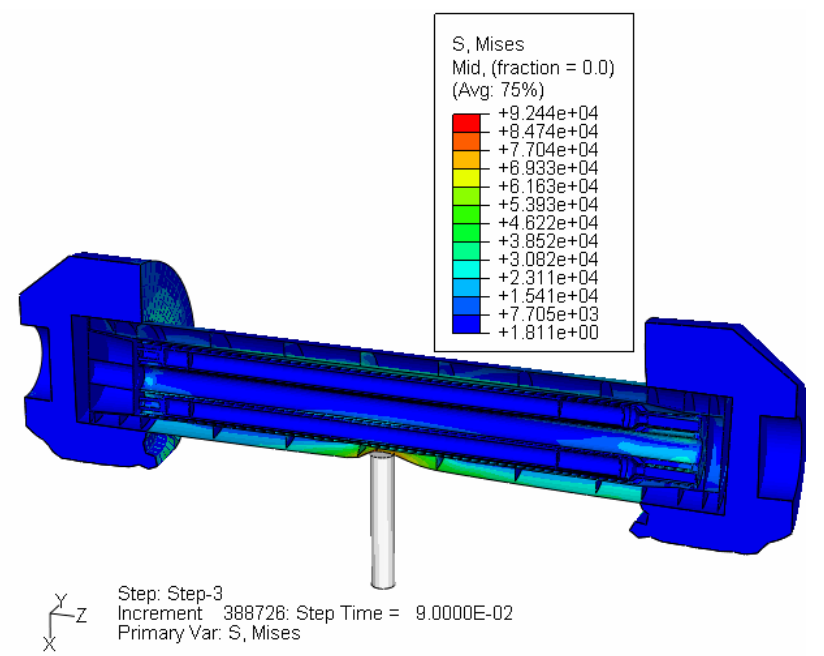

Figure 10. von Mises Stresses in Full Model Caused by Maximum Puncture Load

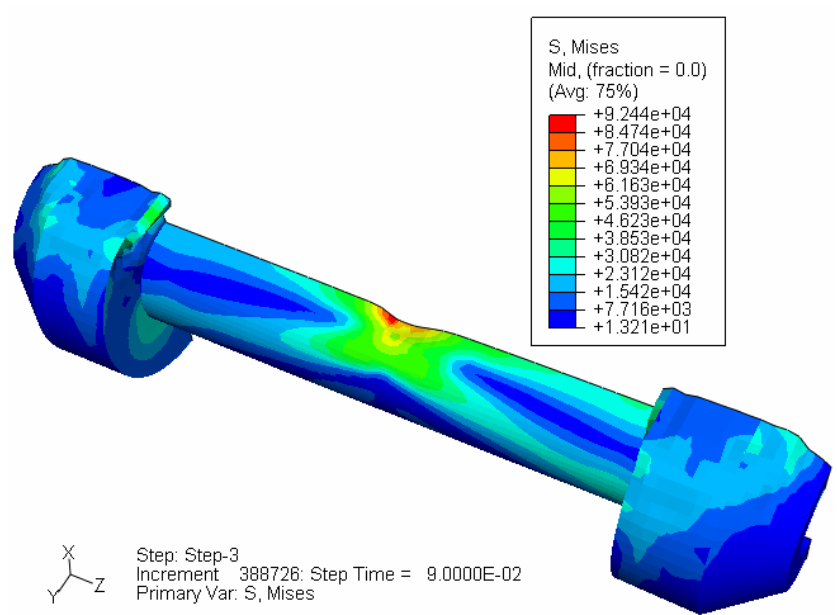

Figure 11. von Mises Stresses in Containment Vessel and Impact Limiter Shells Caused by Maximum Puncture Load

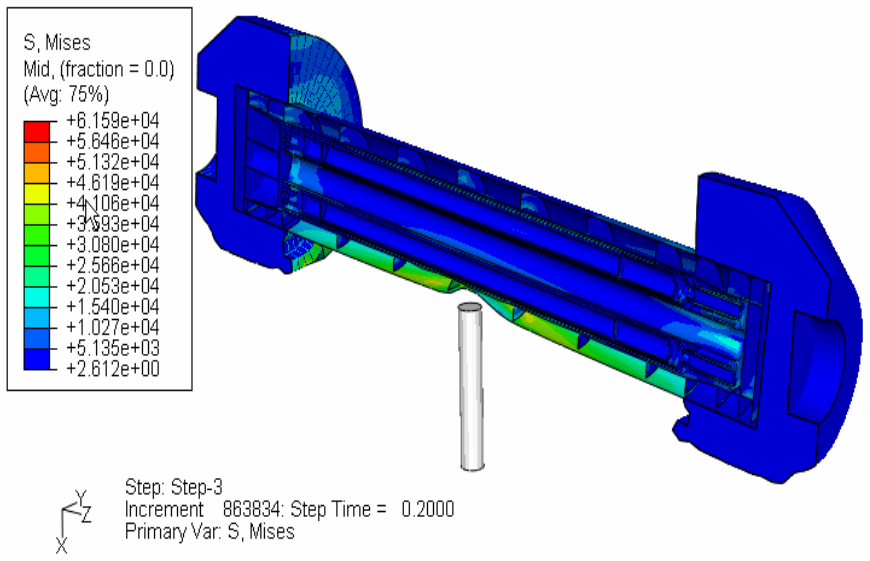

Figure 12. von Mises Stresses in Containment Vessel and Impact Limiter Shells When the Package Rebounds after the 40-inch Puncture

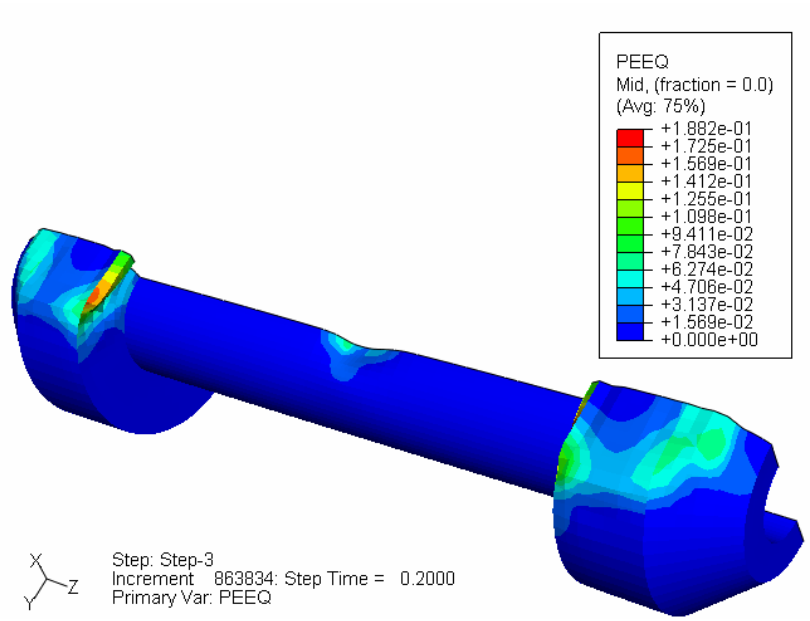

Figure 13. Cumulative Damage in the Overall Model caused by the Sequential Loads of a 30-foot Drop and a 40-inch Puncture 


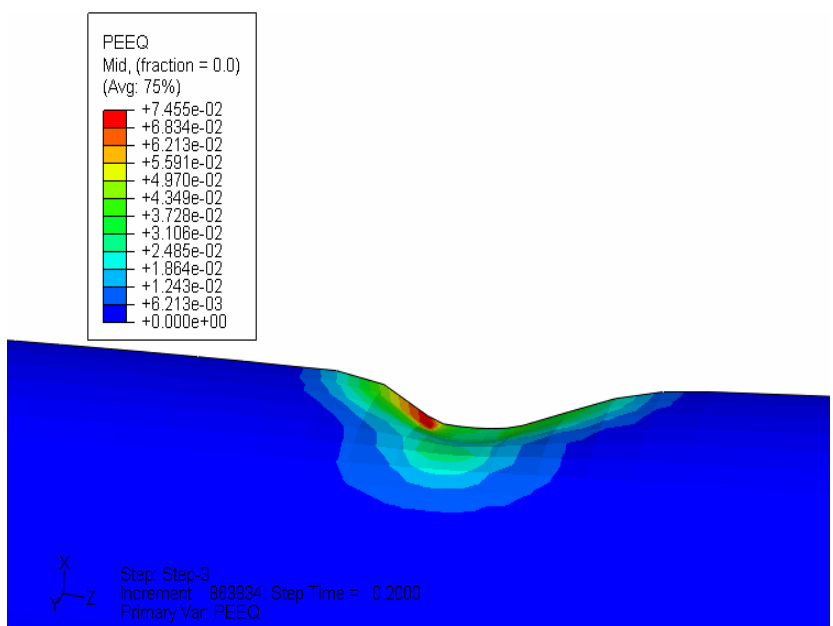

Figure 14. Cumulative Damage in the Containment Vessel caused by the Sequential Loads of a 30-foot Drop and a 40-inch Puncture

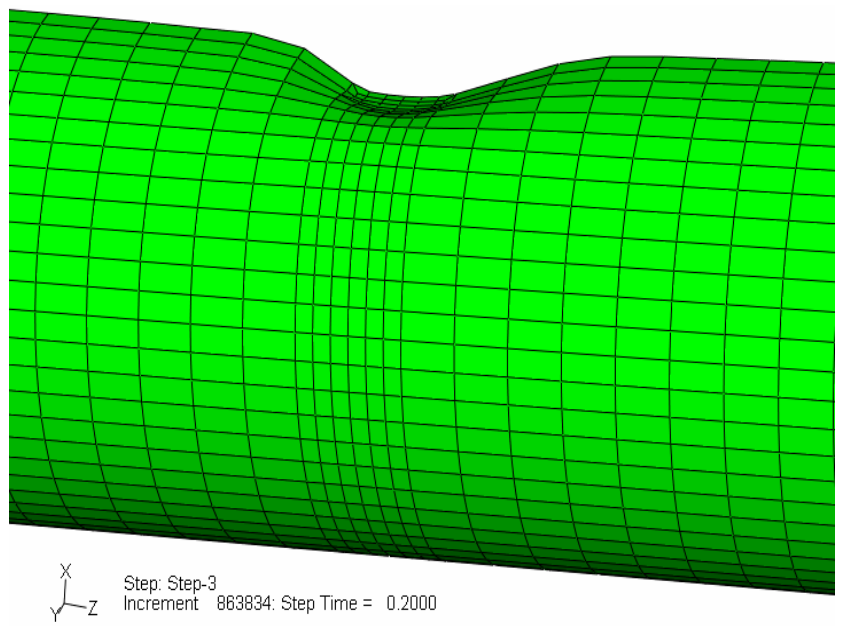

Figure 15. Maximum Indentation in Containment Vessel Caused by a 40 -inch Puncture Analysis

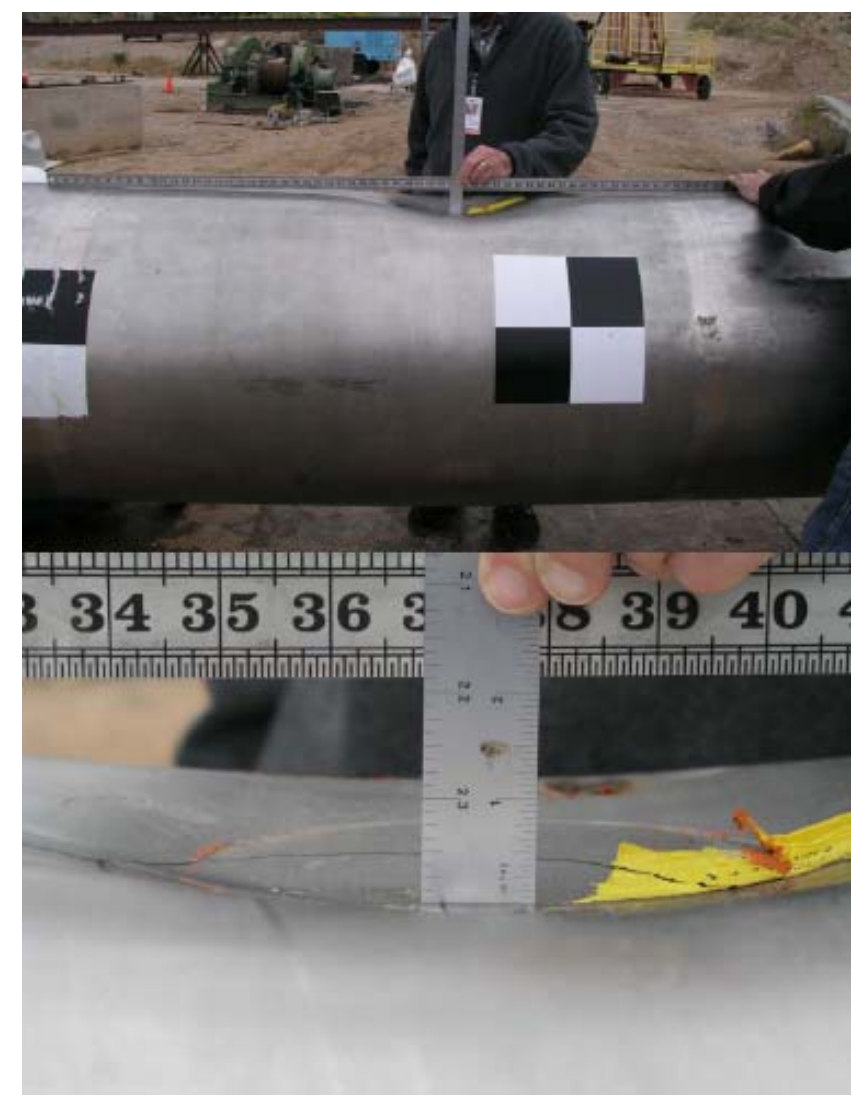

Figure 16. Maximum Indentation in Containment Vessel Caused by a Lateral 40-inch Puncture Test 